\title{
Tribocorrosion Properties of PEO Coatings Produced on AZ91 Magnesium Alloy with Silicate- or Phosphate-Based Electrolytes
}

\author{
Luca Pezzato ${ }^{1}$, Dragos Vranescu ${ }^{1}$, Marco Sinico ${ }^{2}$, Claudio Gennari ${ }^{1}$ (i), \\ Alessio Giorgio Settimi ${ }^{1}$, Pietro Pranovi ${ }^{2}$, Katya Brunelli ${ }^{1,3, *}$ and Manuele Dabalà ${ }^{1}$ \\ 1 Department of Industrial Engineering, University of Padova, Via Marzolo 9, 35131 Padova, Italy; \\ luca.pezzato@unipd.it (L.P.); d.vranescu@gmail.com (D.V.); claudio.gennari1@gmail.com (C.G.); \\ alessio.settimi@gmail.com (A.G.S.); manuele.dabala@unipd.it (M.D.) \\ 2 Il Sentiero International Campus s.r.l, Via Friuli 11, 36015 Vicenza, Italy; \\ marco.sinico@ecor-international.com (M.S.); pietro.pranovi@ecor-research.com (P.P.) \\ 3 Department of Civil, Environmental and Architectural Engineering, University of Padova, Via Marzolo 9, \\ 35131 Padua, Italy \\ * Correspondence: katya.brunelli@unipd.it; Tel.: +39-49-8275500
}

Received: 27 April 2018; Accepted: 21 May 2018; Published: 25 May 2018

\begin{abstract}
In this work, the tribocorrosion behavior of plasma electrolytic oxidation (PEO)-coated AZ91 samples was studied. In particular, two different coatings were produced and compared. One was obtained with an alkaline electrolyte containing sodium phosphate, whereas the other one was produced with an alkaline electrolyte containing sodium silicate. The coatings were characterized with SEM-EDS and XRD techniques, and after the tribocorrosion tests, the wear scars were analyzed with SEM-EDS. The tribocorrosion behavior was evaluated measuring the OCP during a pin on disk test performed in an aggressive environment. Moreover, potentiodynamic polarization and electrochemical impedance spectroscopy tests were performed, to evaluate the corrosion resistance of the different samples in the absence of wear phenomena. The behavior of all the PEO-treated specimens was compared with the one of the untreated sample. A remarkable increase in the tribocorrosion performances after the PEO treatments was observed. Moreover, the samples obtained with the electrolyte containing silicates showed higher tribocorrosion performances.
\end{abstract}

Keywords: plasma electrolytic oxidation; tribocorrosion; magnesium alloy; corrosion

\section{Introduction}

Magnesium alloys are very promising, especially for automotive and aerospace applications, where reducing both fuel consumption and associated emission is the main goal [1]. However, these alloys are characterized by low wear resistance and poor corrosion resistance, primarily attributed to the high chemical activity of magnesium and to the unstable imperfect natural oxide film on its surface $[2,3]$.

Tribocorrosion is the process that leads to the degradation of a metallic and/or non-metallic material for the combined effect of the mechanical contact (sliding, friction, impact) with the corrosive action of the surrounding environment [4]. In order to increase tribocorrosion properties of metals a wide range of coatings have been developed, including those based on ceramics, polymers, and composites, as well as diamond-like carbon (DLC) thin films [5]. Among these, plasma electrolytic oxidation (PEO) seems one of the most promising in order to protect light alloys. PEO is similar to traditional anodizing but the treatments are performed at higher currents and voltages obtaining layers with increased mechanical and corrosion properties [6-8]. The key of the process are the 
micro-discharges formed during the treatment due to the high voltage; in fact, their presence permits the growth of the protective oxide coating [9-12]. The PEO coated samples can be employed in several applications for their high corrosion resistance, which can be also further increased with post-treatments of the surface $[13,14]$, and for their high mechanical properties $[15,16]$.

The tribocorrosion properties of PEO coatings produced on aluminum and titanium alloys have already been studied, as reported in the literature. Garsivazjazi et al. found that that the increase of the voltage produces an increase of the tribocorrosion properties of grade 5 titanium alloy [17]. Considering the tribocorrosion behavior of PEO-coated aluminum alloys, Barik et al. demonstrated the higher erosion-corrosion resistance with either cast or HVOF sprayed nickel-aluminum bronze surfaces and related this superior performance to the higher hardness of PEO coatings, in comparison to the others [18]. Nie et al. reported of improved abrasive wear and corrosion resistance for PEO coatings on AA 6082 if compared with the untreated aluminum alloy [19].

However, only a few works in the literature can be found regarding the tribocorrosion performances of PEO coatings produced on magnesium alloys [20-22], as compared with the ones regarding aluminum and titanium alloys.

In this work, PEO coatings were produced on AZ91 magnesium alloy using two different electrolytes, silicate or phosphate, and the resulting coated samples were analyzed by tribocorrosion tests. Moreover, potentiodynamic polarization and dry wear tests were performed to study the interaction of corrosion and tribological effect on the resulting tribocorrosion performances. The behavior of an untreated sample was used for comparison.

\section{Experimental}

Samples of AZ91D alloy were used as substrate for PEO coatings. The composition of the alloy is reported in Table 1.

Table 1. Composition of AZ91 magnesium alloy (wt \%).

\begin{tabular}{ccccccc}
\hline $\mathbf{M g}$ & $\mathbf{A l}$ & $\mathbf{Z n}$ & $\mathbf{S i}$ & $\mathbf{M n}$ & $\mathbf{F e}$ & $\mathbf{C u}$ \\
\hline 90.8 & $8.5-9.5$ & 0.7 & 0.35 & 0.18 & 0.014 & 0.003 \\
\hline
\end{tabular}

The samples, before PEO treatment, were polished with standard metallographic techniques and degreased with acetone by ultrasound.

Two different electrolytes, both in aqueous solution, were used to produce the PEO coatings. The first solution contained $25 \mathrm{~g} / \mathrm{L}$ of $\mathrm{NaOH}, 100 \mathrm{~g} / \mathrm{L}$ of $\mathrm{Na}_{2} \mathrm{O}_{3} \mathrm{Si}$, and the corresponding samples were identified as "PEO-Si"; the second one contained $25 \mathrm{~g} / \mathrm{L}$ of $\mathrm{NaOH}, 100 \mathrm{~g} / \mathrm{L}$ of $\mathrm{Na}_{5} \mathrm{P}_{3} \mathrm{O}_{10}$, and the samples were named "PEO-P".

A TDK-Lambda DC power supply of $300 \mathrm{~V} / 8$ A capacity was used to produce PEO coatings on the magnesium samples. A carbon steel mesh was used as a cathode and the treatments were performed in galvanostatic mode. In detail, the treatments were performed working at $0.5 \mathrm{~A} / \mathrm{cm}^{2}$ for two minutes.

Distilled water and ethanol were employed to wash the samples that were then dried with compressed air. The surfaces of the samples were observed with a Zeiss Stemi 2000-C stereo microscope (Carl Zeiss AG, Oberkochen, Germany) in order to obtain information on the quality of the coatings (Figure 1). The values of roughness of the surface on the samples of PEO-Si and PEO-P are similar: $R_{\mathrm{a}}=2.78 \mu \mathrm{m}$ and $R_{\mathrm{q}}=3.52 \mu \mathrm{m}$ for the sample PEO-Si, and $R_{\mathrm{a}}=2.96 \mu \mathrm{m}$ and $R_{\mathrm{q}}=3.98 \mu \mathrm{m}$ for the sample PEO-P. The cross-section of the samples was cut and mounted in resin, ground using $\mathrm{SiC}$ abrasive papers, and finally polished with cloth and a diamond suspension ( 6 and $1 \mu \mathrm{m})$. 
A

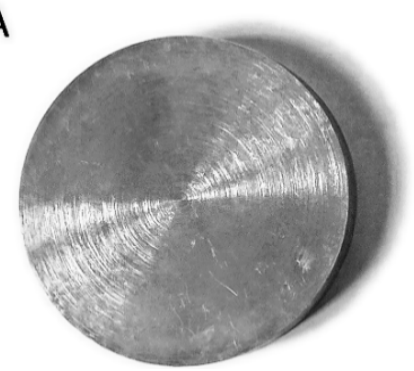

B

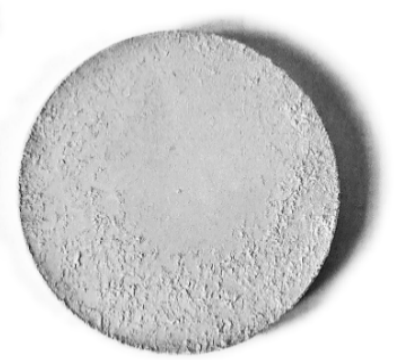

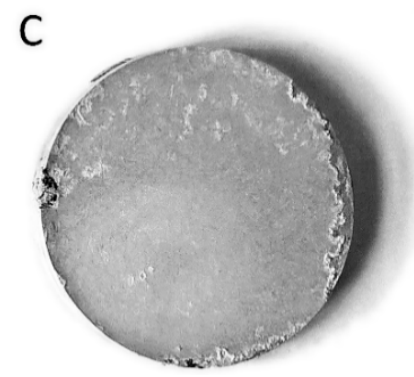

Figure 1. Stereo images of: (A) untreated sample; (B) sample PEO-Si; and (C) sample PEO-P.

A Cambridge Stereoscan 440 scanning electron microscope, equipped with a Philips PV9800 EDS (Leica Cambridge Ltd, Cambridge, England), was used to analyze the surface and the cross-section of the samples in order to identify the coating thickness, the microstructure, the porosity and other features of the surface.

The micro-hardness was evaluated with a Vickers micro-hardness test on the cross-sections of the samples using a $50 \mathrm{~g}$ load.

The corrosion behavior was evaluated with electrochemical methods: potentiodynamic polarization and electrochemical impedance spectroscopy (EIS) tests. Both of the tests were performed using as electrolyte a solution containing $0.1 \mathrm{M} \mathrm{Na}_{2} \mathrm{SO}_{4}$ and $0.05 \mathrm{M} \mathrm{NaCl}$. For the potentiodynamic polarization tests an AMEL 2549 potentiostat (Amel S.r.l., Milano, Italy) was employed. As a reference electrode a saturated calomel electrode (SCE) was used and a platinum electrode was employed as the counter electrode. The tests were performed with a scan rate of $0.4 \mathrm{mV} / \mathrm{s}$. The impedance measurements were performed with a Materials Instrument Spectrometer connected with the 2549 potentiostat working at the open circuit voltage $(\mathrm{OCV})$, using a range of frequencies between $10^{5} \mathrm{~Hz}$ and $10^{-2} \mathrm{~Hz}$ and a perturbation amplitude of $10 \mathrm{mV}$. The data from EIS tests were then fitted with the software Z-View (version 3.3).

The tribocorrosion tests were performed with the Tribo-corr equipment, as illustrated in Figure 2, which allows the study of the influence of environmental factors (chemical and/or electrochemical) on the tribological behavior of surfaces.

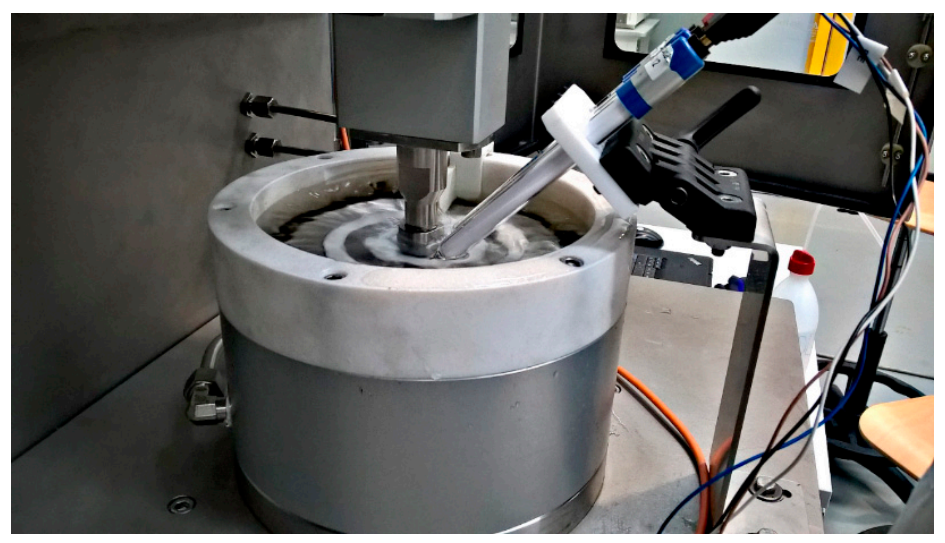

Figure 2. Equipment for the tribocorrosion test.

It consists of a rotary housing for the sample, with an O-ring that avoids the loss of liquid. The rotary housing is located at the bottom of a tank that contains the electrolyte and is also equipped with electrodes holder. The electrolyte circulation takes place through a system of two pumps. The pin is lowered with a $20 \mathrm{~N}$ force after $1 \mathrm{~min}$ of free rotation of the sample, to reach a working speed of $0.2 \mathrm{~m} / \mathrm{s}$. The system is connected with two platinum electrodes as counter electrodes and a calomel electrode as the reference. The test is a pin on disk test where the disk is the plasma electrolytic 
oxidation (PEO)-treated sample and the pin, an alumina ball (10 mm diameter, hardness $1610 \mathrm{HV}$ ). Before the test the sample was left immersed for $30 \mathrm{~min}$ for open circuit potential (OCP) stabilization. In detail each test lasted $62 \mathrm{~min}$ and consists of four phases:

- the sample is left immersed in the electrolyte for $5 \mathrm{~min}$ for OCP stabilization;

- the OCP value is measured for the following 20 min without any wear;

- the pin is lowered with a force of $20 \mathrm{~N}$ and the OCP value is measured; this phase lasts $1000 \mathrm{~s}$;

- finally, the OCP value is again measured without wear for another $20 \mathrm{~min}$.

After the tests, wear scar depths were evaluated by stylus profilometry. After the tribocorrosion tests, the wear paths were analyzed by stereo microscopy and scanning electron microscopy. Additionally, a standard dry wear test was performed on the samples as a comparison.

\section{Results and Discussion}

\subsection{Surface Analysis}

Both the surface and the cross-section of the PEO-treated samples, obtained using the two different electrolytes, were investigated with SEM and EDS analysis (Figure 3, Table 2). All samples showed the typical surface formed on PEO-coated light alloys, rich of pores and micro cracks [23], even if with some differences. In fact, the surface of sample PEO-P was more homogeneous and porous in comparison with the one of the PEO-Si sample. The composition of the surfaces was rich in silicate compounds in the PEO-Si samples, and in phosphate compounds in the PEO-P ones, in accordance with the composition of the substrate and of the electrolytes. Considering the cross-sections of the samples, it can be observed that the coating in the PEO-Si sample was thicker, more adherent, and uniform than in the PEO-P one. The average thickness of the coating was $100 \mu \mathrm{m}$ in the PEO-Si sample and $40 \mu \mathrm{m}$ in the PEO-P sample. In both of the samples, the typical double-layer structure of the PEO coatings was present, with the inner barrier layer, which provides the major protection against corrosion, and the external porous layer [24]. Considering the composition of the different layers, (Table 2), in the PEO-Si sample an enrichment in Mg and impoverishment in Si can be observed passing from the porous external layer to the inner barrier layer. In the PEO-P sample an enrichment in $\mathrm{Mg}$ and an impoverishment in $\mathrm{P}$ can be observed in the porous layer.
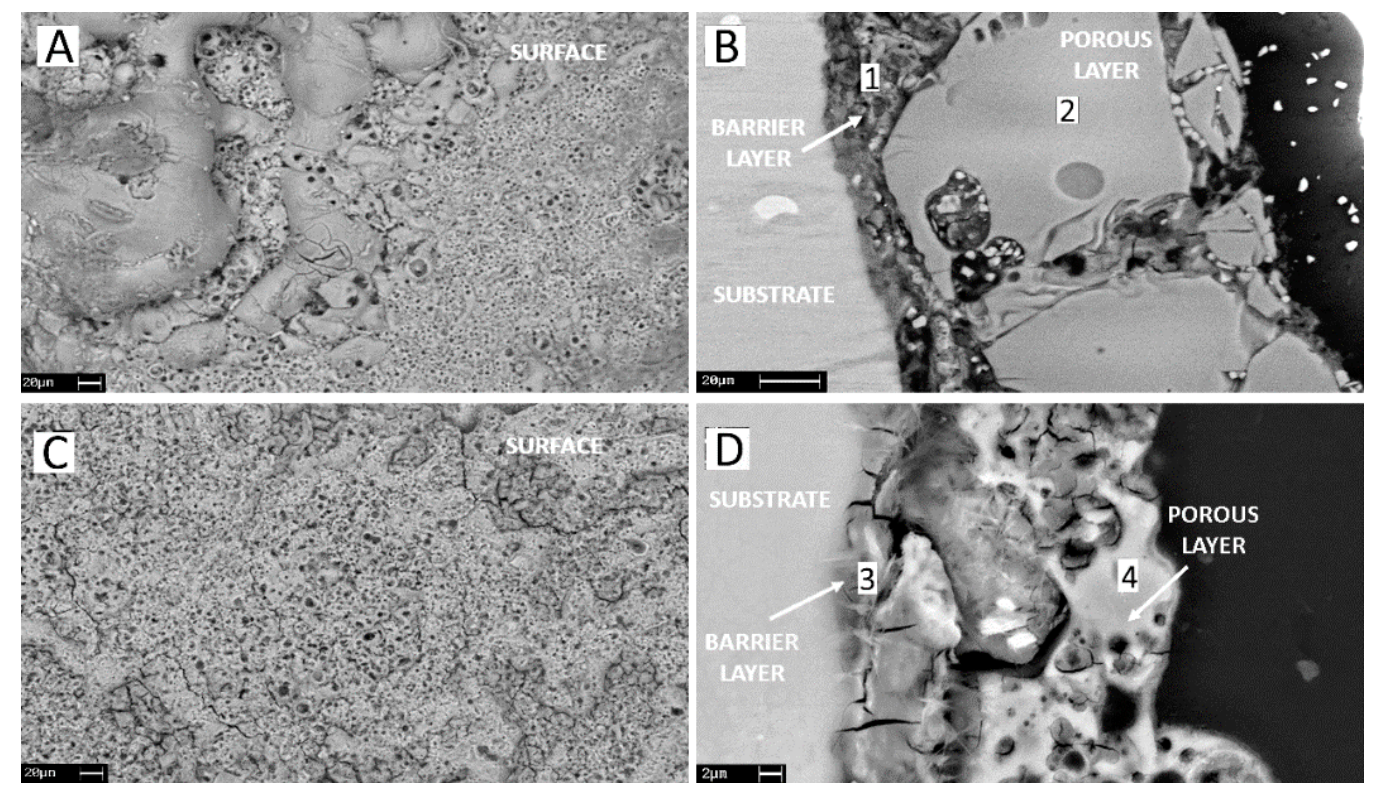

Figure 3. SEM-BSE images of the surface of the sample PEO-Si (A) and PEO-P (C), and of the cross-sections of the sample PEO-Si (B) and PEO-P (D). 
Table 2. EDS microanalysis (wt \%) obtained on different zones of the surface and cross section of the samples PEO-Si and PEO-P.

\begin{tabular}{ccccccc}
\hline Zone/Sample & $\mathbf{O}$ & $\mathbf{N a}$ & $\mathbf{M g}$ & $\mathbf{A l}$ & $\mathbf{S i}$ & $\mathbf{P}$ \\
\hline Surface PEO-Si & 50.9 & 9.8 & 18.2 & 1.0 & 20.1 & - \\
Barrier layer PEO-Si (1) & 47.4 & 10.9 & 22.5 & 1.4 & 17.8 & - \\
Porous layer PEO-Si (2) & 48.2 & 5.7 & 16.7 & 1.8 & 27.6 & - \\
Surface PEO-P & 45.2 & 7.1 & 24.4 & 2.9 & - & 20.4 \\
Barrier layer PEO-P (3) & 52.0 & 5.6 & 16.7 & 4.3 & - & 21.3 \\
Porous layer PEO-P (4) & 48.7 & 5.3 & 22.9 & 2.9 & - & 20.2 \\
\hline
\end{tabular}

Considering the different phases formed, the coating of the PEO-Si sample was composed of $\mathrm{MgO}$, $\mathrm{Mg}_{2} \mathrm{SiO}_{4}$, and $\mathrm{MgAl}_{2} \mathrm{O}_{4}$, whereas that of the PEO-P sample was $\mathrm{MgO}, \mathrm{MgAl}_{2} \mathrm{O}_{4}$, and $\mathrm{Mg}\left(\mathrm{PO}_{3}\right)$, as reported by the authors in $[8,13]$. In both cases, metallic $\mathrm{Mg}$ was also found due to the influence of the substrate. In the same works XPS analysis was also performed and this confirmed the different phases coming from XRD. The phases present in the PEO coatings were in accordance with the composition of the substrate and of the electrolyte [25].

\subsection{Corrosion Resistance}

The corrosion resistance of the PEO-treated samples with different electrolytes was evaluated with potentiodynamic polarization and EIS tests in an electrolyte containing both sulfates and chlorides.

The potentiodynamic polarization curves are shown in Figure 4 and the values of the extrapolated current densities $\left(i_{\text {corr }}\right)$ and corrosion potentials $\left(E_{\text {corr }}\right)$ are reported in Table 3.

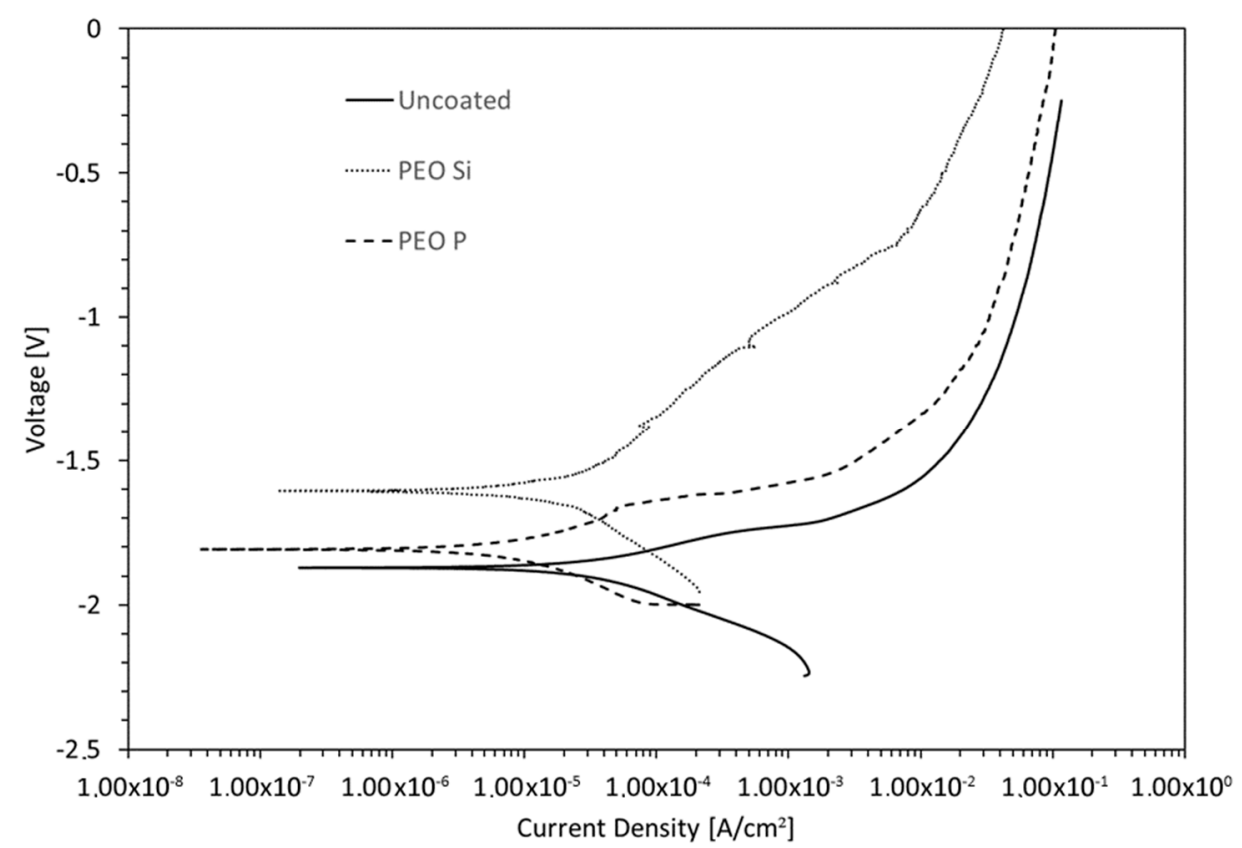

Figure 4. Potentiodynamic polarization curves of the samples PEO-Si and PEO-P (test electrolyte: $0.1 \mathrm{M} \mathrm{Na}_{2} \mathrm{SO}_{4}$ and $0.05 \mathrm{M} \mathrm{NaCl}$ ). 
Table 3. Corrosion potentials and corrosion current density extrapolated from the potentiodynamic polarization plot.

\begin{tabular}{ccc}
\hline Sample & $\boldsymbol{I}_{\text {corr }}\left[\mathbf{A} / \mathbf{c m}^{2}\right]$ & $E_{\text {corr }}[\mathbf{V}]$ \\
\hline Uncoated & $8 \times 10^{-5}$ & -1.9 \\
PEO Si & $1 \times 10^{-5}$ & -1.6 \\
PEO P & $8 \times 10^{-6}$ & -1.8 \\
\hline
\end{tabular}

A remarkable decrease of the corrosion current density of both the PEO-treated samples can be observed in comparison with the untreated one. Considering the two PEO-coated samples, an increase in the corrosion potential was found for the PEO-Si sample. EIS tests were also performed to better study the corrosion behavior of the obtained coatings. Fitting of the experimental data was performed with Z-view software, using the equivalent circuits reported in Figure 5. In detail, for the untreated sample the R/CPE circuit was chosen because only the natural oxide layer is present (Figure 5A). For the PEO coated samples the equivalent circuit reported in Figure $5 \mathrm{~B}$ was used, in accordance with the literature [26,27], to consider the effect of the two layers, the external porous layer and the internal layer, often called barrier layer.

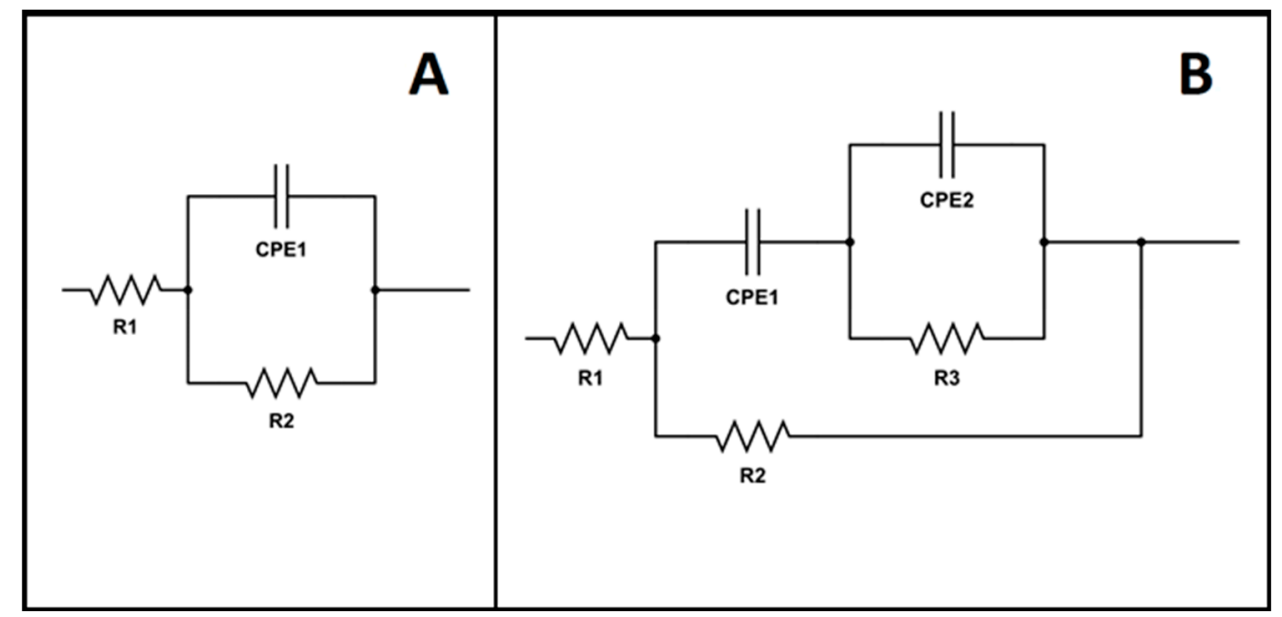

Figure 5. Equivalent circuits employed for curve fitting for the untreated sample (A) and PEO-coated samples (B).

The detailed description of the parameters in the equivalent circuit is reported in a previous work [28].

The results of EIS tests (Nyquist Plot in Figure 6 and fitting of the experimental data in Table 4) substantially confirmed the results obtained from potentiodynamic polarization. In fact, both the PEO-treated samples exhibited improved corrosion performances. In comparison to the untreated sample, an increase of about one order of magnitude in the polarization resistance resulted. Considering the effect of different electrolytes, it can be observed that the PEO-P sample was characterized by a higher value of the polarization resistance, in accordance with the lower corrosion current density, recorded during potentiodynamic polarization tests. 


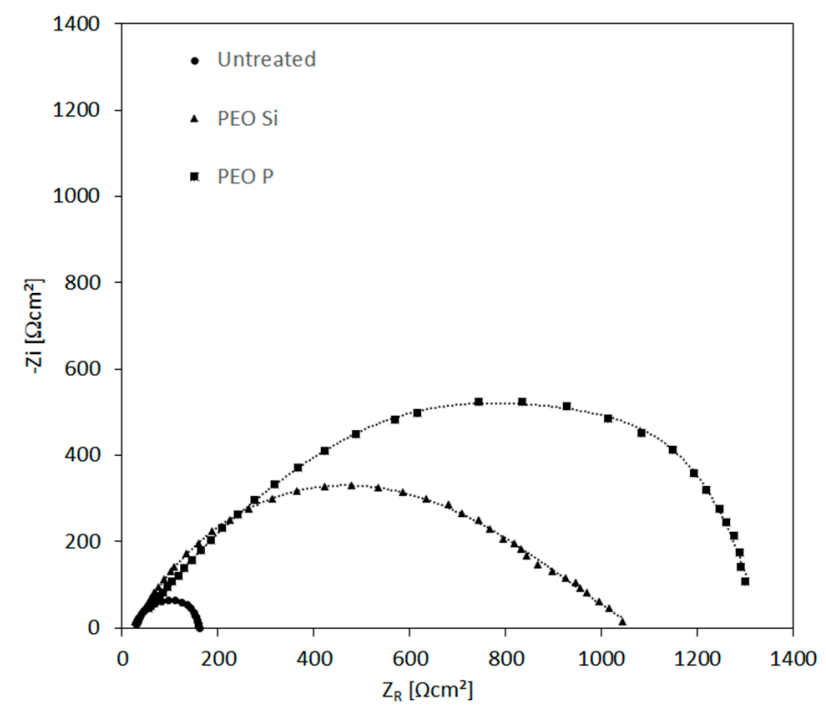

Figure 6. Nyquist plots of the PEO-Si and PEO-P samples (test electrolyte: $0.1 \mathrm{M} \mathrm{Na}_{2} \mathrm{SO}_{4}$ and $0.05 \mathrm{M} \mathrm{NaCl})$.

Table 4. Results of the fitting of the experimental data obtained from EIS tests.

\begin{tabular}{cccc}
\hline Parameter & Uncoated & PEO-Si & PEO-P \\
\hline$R_{1}\left[\Omega \mathrm{cm}^{2}\right]$ & 29 & 30 & 30.95 \\
$R_{2}\left[\Omega \mathrm{cm}^{2}\right]$ & 140 & 120 & 150 \\
$R_{3}\left[\Omega \mathrm{cm}^{2}\right]$ & - & 909 & 1372 \\
$Q_{2}\left[\mathrm{~F} \mathrm{~Hz}^{1-\mathrm{n}}\right]$ & - & $7.7 \times 10^{-5}$ & $1.27 \times 10^{-5}$ \\
$n_{2}$ & - & 0.74 & 0.73 \\
$Q_{1}\left[\mathrm{~F} \mathrm{~Hz}^{1-\mathrm{n}}\right]$ & $7.8 \times 10^{-6}$ & $7.6 \times 10^{-7}$ & $2.71 \times 10^{-7}$ \\
$n_{1}$ & 0.93 & 0.9 & 0.94 \\
$\chi^{2}$ & 0.0005 & 0.0006 & 0.0003 \\
\hline
\end{tabular}

\subsection{Micro-Hardness}

The hardness of the coating was measured on the cross-section of the samples with a micro-Vickers indenter. The value obtained on the coating was compared with the hardness of the substrate and the results are reported in Table 5.

Table 5. Results of micro-hardness tests.

\begin{tabular}{cc}
\hline Sample & Micro-Hardness $\mathbf{H V}_{\mathbf{0 . 0 5}}$ \\
\hline Substrate & 54 \\
PEO-Si & 359 \\
PEO-P & 353 \\
\hline
\end{tabular}

From the reported data it can be noted that the hardness of the coatings is, as predictable, remarkably higher in comparison with the one of the substrate. Comparing the PEO-Si and PEO-P samples, the hardness values were similar.

\subsection{Tribocorrosion}

The results of the tribocorrosion tests in terms of OCP vs. time, according to ASTM G119-04, are reported in Figure 7. 


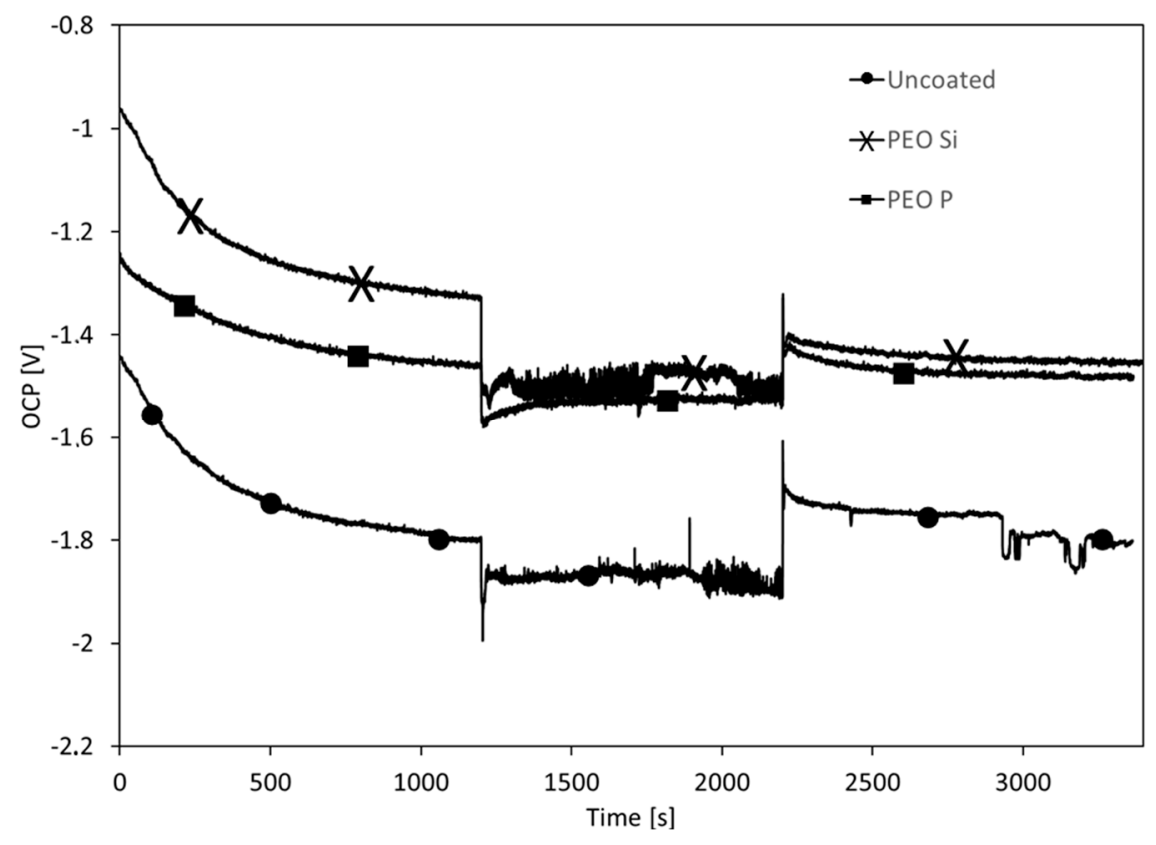

Figure 7. OCP vs. time plot during the tribocorrosion tests of the different samples.

In the graph, the first $1200 \mathrm{~s}$ correspond to the immersion of the sample without any wear, the subsequent $1000 \mathrm{~s}$ to the real tribocorrosion test, and the last $1200 \mathrm{~s}$ to another immersion without any wear. All the samples showed the same behavior: a stabilization of the OCP during the first immersion of $20 \mathrm{~min}$, a decrease of the OCP during the tribocorrosion tests and, finally, a return of the $\mathrm{OCP}$ to higher values, due to the re-passivation of the sample. The differences among the samples can be observed regarding the value of the OCP. In fact, both the PEO-treated samples are characterized, for the whole length of the tests, by higher values of the OCP than the untreated sample, thus, indicating that the PEO treatment increases the tribocorrosion performances of the samples. Comparing the PEO-P and PEO-Si samples, the OCP of the sample obtained in the electrolyte containing silicates is, in each step of the test, higher, indicating an increase in the tribocorrosion resistance for the PEO-Si sample. The friction coefficient $\mu$ was measured during the tribocorrosion test finding an average value of 0.9 for the untreated sample, 1.3 for the PEO-P sample, and 1.4 for the PEO-Si sample. No significant differences were found for the two PEO-treated samples, but an increase in the friction coefficient after the PEO treatment was recorded, in accordance with the literature [16]. The friction coefficients were also measured during dry sliding tests and a decrease ( 0.7 for the untreated sample, 1.1 for the PEO-P, and 1.2 for the PEO-Si), in comparison with the ones measured during tribocorrosion tests, was found.

The wear depth after the tribocorrosion test resulted of $212 \mu \mathrm{m}$ for the untreated sample, $104 \mu \mathrm{m}$ for the sample PEO-Si, and $160 \mu \mathrm{m}$ for the sample PEO-P. These results confirmed the ones obtained from OCV test and showed that the sample PEO-Si was characterized by improved tribocorrosion performance, if compared with the PEO-P one. Moreover, both the PEO-treated samples were characterized by a lower wear depth than the untreated sample. To further validate this result, and to understand the mechanism of damage of the coatings, the samples after the tribocorrosion tests were observed with stereo and electron microscopy. All the samples were also analyzed after a standard wear test with the same load as the tribocorrosion tests in order to determine eventual differences in the response of the coatings.

The images of the surfaces of the different samples after standard wear and tribocorrosion tests can be observed in Figure 8. 
A

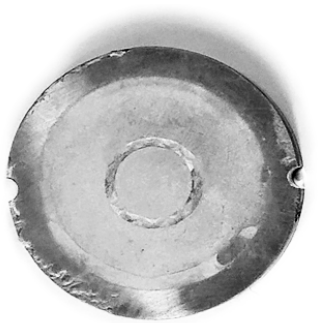

D

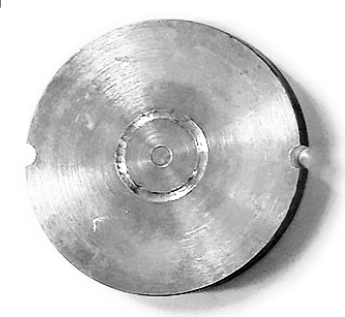

B

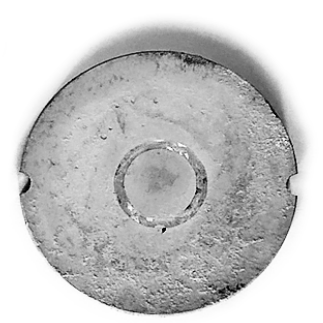

$E$

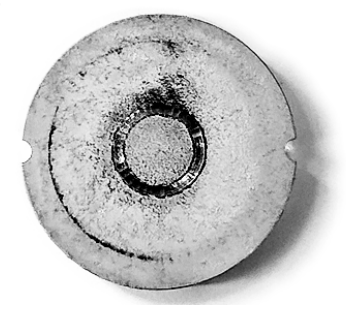

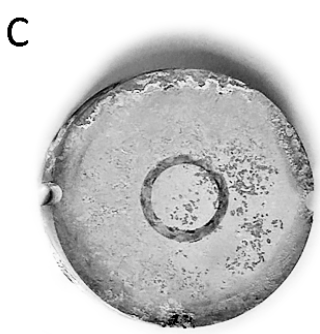

$\mathrm{F}$

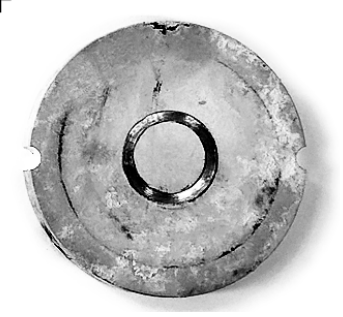

Figure 8. Surface of the samples after tribocorrosion test (A) untreated; (B) PEO-Si; and (C) PEO-P; and standard wear tests (D) untreated; (E) PEO-Si; and (F) PEO-P.

Considering the samples after the tribocorrosion test, the presence of corrosion products on the surface of the untreated sample was observed (Figure 8A) and the coating resulted have greater adherence in the PEO-Si sample than in the PEO-P sample (Figure 8B,C). After the standard wear test, no significant differences were evident on the surface of the two PEO-treated samples from macroscopic observation (Figure 8E,F) and the surface of the untreated sample (Figure 8D) was bright with the presence of the wear track, visible also on the PEO-treated sample. To better analyze the conditions of the coatings after the dry and the tribocorrosion tests, a more detailed analysis at the interface between the wear track and the coating was performed. The results of the stereo-microscope observation are reported in Figure 9, whereas the SEM images obtained with secondary electrons are shown in Figure 10.
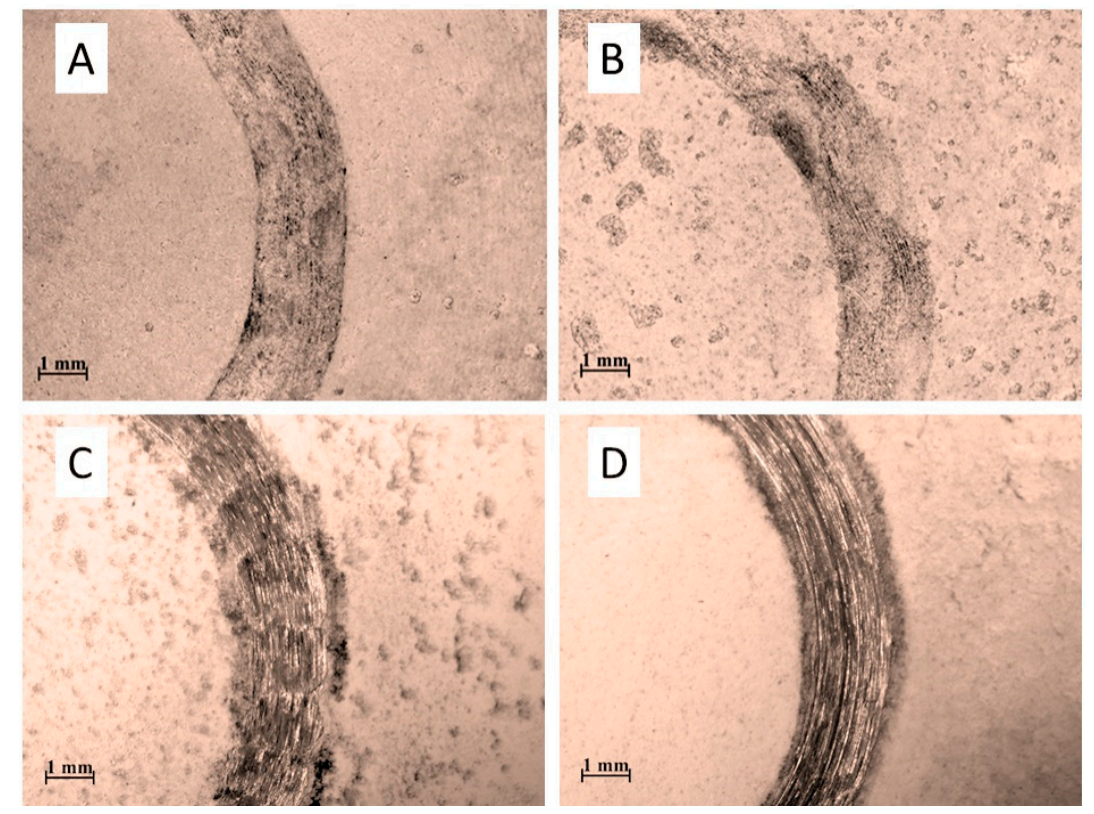

Figure 9. Stereomicroscope images of the surface of the samples after tribocorrosion test (A) PEO-Si; and (B) PEO-P; and standard wear tests (C) PEO-Si; and (D) PEO-P. 

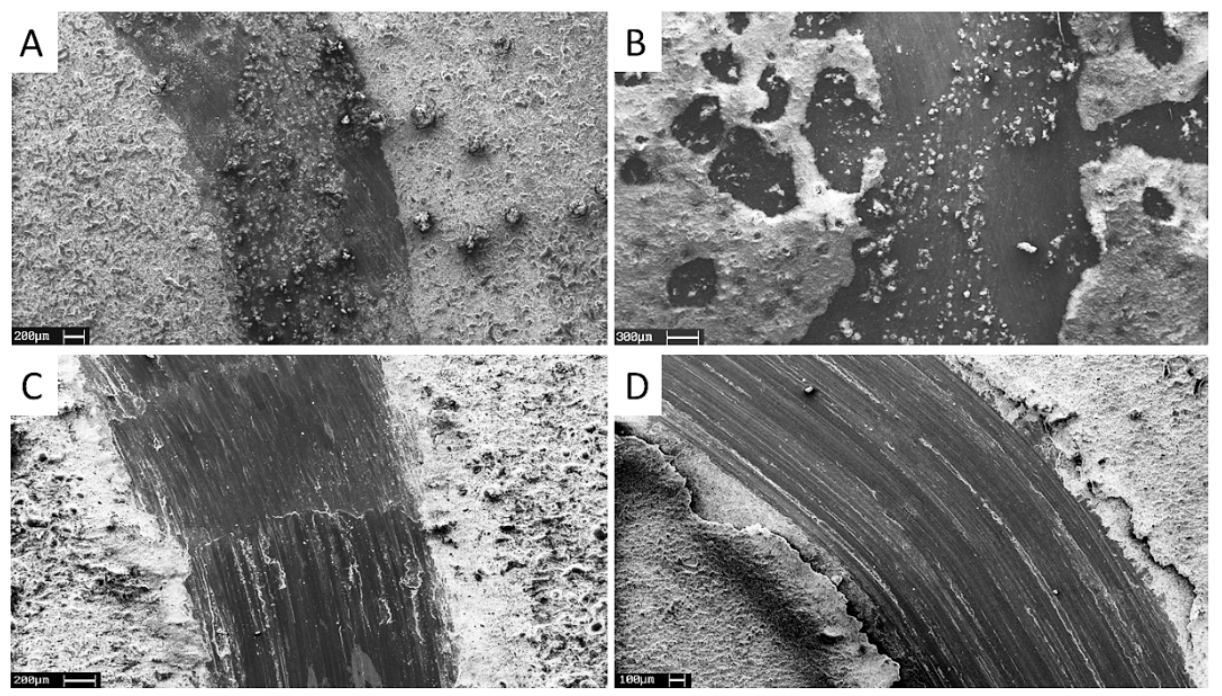

Figure 10. SEM-SE images (secondary electrons) of the surface of the samples after the tribocorrosion test (A) PEO-Si; and (B) PEO-P; and standard wear tests (C) PEO-Si; and (D) PEO-P.

After tribocorrosion tests, the interface between the wear track and the coating in the PEO-P sample was totally damaged and detached, whereas the coating of the PEO-Si sample was remarkably more adherent and undamaged (Figures 9A,B and 10A,B). This fact can be ascribed to a different mechanism of corrosion in the two samples. As a matter of fact, Liang et al. [29] found that in PEO samples, obtained in phosphate solution, corrosion products formed at the interface between the substrate and coating, leading to the detachment of the latter, whereas in PEO samples, obtained in silicates solution, the corrosion products formed only in the pores of the coating After the standard dry tests the situation is different; in fact, the interfaces between the wear track and the coating in the PEO-P and PEO-Si samples were similar (Figures 9C,D and 10C,D), suggesting that the adhesion of the coating on the substrate and its mechanical properties were not influenced by the type of the electrolyte used in the PEO process, in agreement with the micro-hardness test. Therefore, the behavior of the two coatings in dry conditions was similar, whereas the tribocorrosion behavior was totally different because the formation of corrosion products at the interface substrate/coating in the sample obtained with phosphates caused the detachment of the coating under the tribocorrosion tests, and, consequently, a remarkable decrease in the tribocorrosion properties of this sample.

In order to study the corrosion products formed on the surfaces after the tribocorrosion tests, the samples were observed with SEM in backscattered mode and EDS analyzes were performed (Figure 11 and Table 6). The same analyses were also performed on the samples after dry wear tests, as a comparison. The EDS punctual analysis was performed on the points identified by the numbers in the figures.

From the SEM-BSE images, the darker zones in the wear track suggested the presence of corrosion products, which were mainly composed by sulfates and chlorides (analysis in points 1 and 3). The presence of the corrosion products could explain the increase in the friction coefficient, measured in the samples during the tribocorrosion test if compared with the ones measured during the dry sliding test, as previously reported. The composition of the coating remained more or less the same after the tribocorrosion tests and the dry wear tests, as can be noted from the comparison of the EDS analysis (points 2 and 4 for the samples after the tribocorrosion test and points 5 and 6 after the dry wear test). 

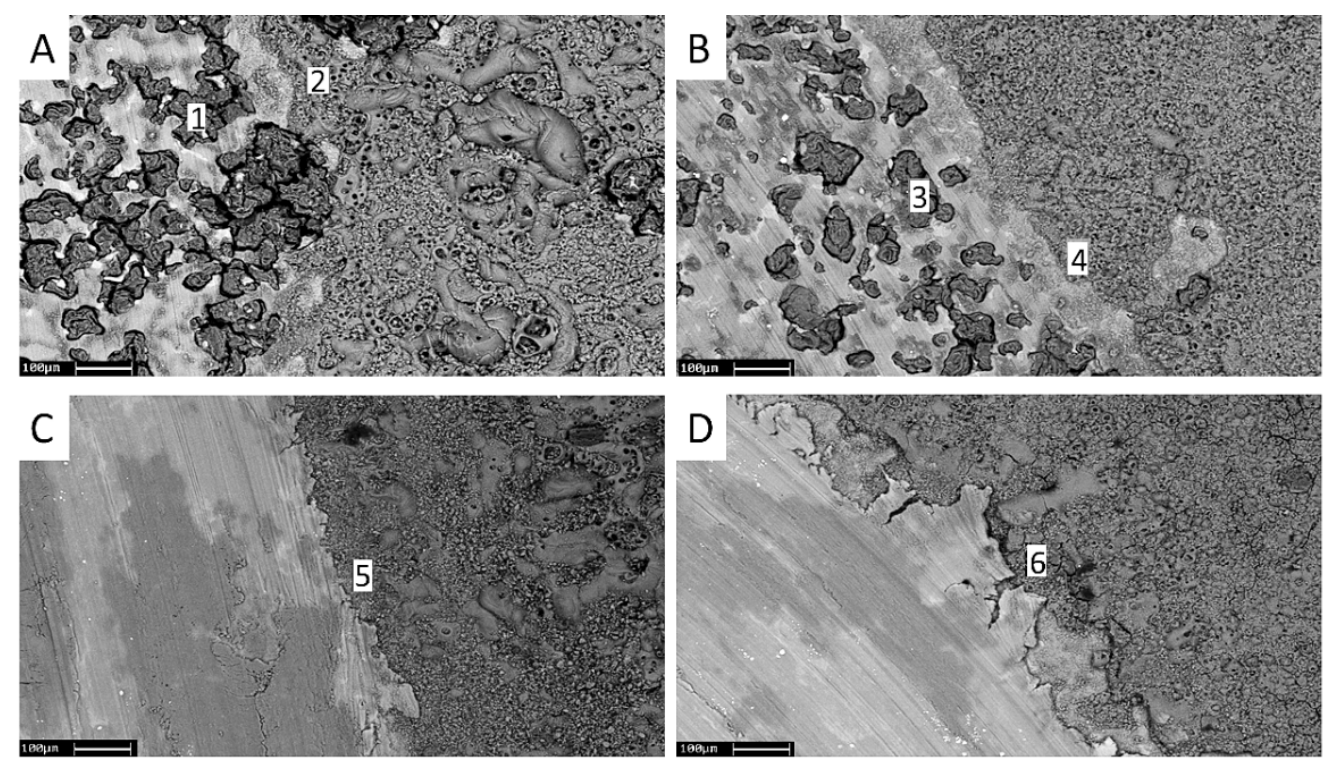

Figure 11. SEM-BSE images (backscattered electrons) of the surface of the samples after tribocorrosion test (A) PEO-Si; and (B) PEO-P; and standard wear tests (C) PEO-Si; and (D) PEO-P.

Table 6. EDS microanalysis (wt \%) obtained on different zones of the samples after corrosion and dry wear test.

\begin{tabular}{cccccccccc}
\hline Zone & Mg & Al & Zn & Na & O & Si & P & Cl & S \\
\hline 1 & 25.8 & 5.6 & 0.9 & 7.2 & 53.9 & - & - & 1.3 & 5.8 \\
2 & 13.8 & 2.0 & 0.7 & 13.0 & 47.3 & 19.7 & - & 0.3 & 3.3 \\
3 & 26.7 & 8.8 & 0.4 & 2.2 & 56.8 & - & 0.4 & 0.5 & 4.3 \\
4 & 26.0 & 2.4 & 0.4 & 7.0 & 44.3 & - & 19.2 & 0.2 & 0.4 \\
5 & 17.6 & 1.8 & 0.2 & 10.6 & 48.5 & 21.3 & - & - & - \\
6 & 26.9 & 2.8 & 0.2 & 7.4 & 48.3 & - & 14.4 & - & - \\
\hline
\end{tabular}

\section{Conclusions}

In this work, the tribocorrosion response of PEO coatings obtained on AZ91D magnesium alloy was studied and compared with an untreated sample. In detail, were studied PEO coatings obtained in DC mode using two different electrolytes: one silicate-based and one phosphate-based. Considering separately the corrosion and mechanical properties, it was found that the PEO-coated samples exhibited similar behavior and improved performances, if compared with the untreated one. They had the same micro-hardness value and showed a similar response to corrosion and dry wear tests. Considering the tribocorrosion performances, the PEO samples were more resistant than the untreated one, even if significant differences between the PEO-Si and PEO-P samples were found. The PEO-Si sample was characterized by a higher tribocorrosion performance than the PEO-P one. In fact, its OCP value was higher during the tribocorrosion tests and its protective coating remained adherent and undamaged. This fact was linked with the different mechanism of corrosion occurring in the PEO-Si sample and in the PEO-P sample. In conclusion, for PEO-coated magnesium alloy the tribocorrosion was also confirmed to be a complex process not directly correlated to the mechanical and corrosion properties considered individually, but more related to the mechanism of damage of the samples.

Author Contributions: Conceptualization, L.P.; Methodology, L.P. and P.P.; Software, D.V., M.S. and C.G.; Validation, L.P.; Formal Analysis, L.P. and D.V.; Investigation, L.P, D.V. and M.S.; Data Curation, L.P., C.G. and A.G.S.; Writing-Original Draft Preparation, L.P.; Writing-Review \& Editing, K.B.; Visualization, L.P.; Supervision, K.B. and M.D.

Funding: This research received no external funding. 
Acknowledgments: Il Sentiero International Campus S.r.l. is gratefully acknowledged for provision of Tribocorrosion Equipment.

Conflicts of Interest: The authors declare no conflict of interest.

\section{References}

1. Mordike, B.L.; Ebert, T. Magnesium properties-applications-potential. Mater. Sci. Eng. A 2001, 302, 37-45. [CrossRef]

2. Wang, L.; Chen, L.; Yan, Z.C.; Wang, H.L.; Peng, J.Z. Growth and corrosion characteristics of plasma electrolytic oxidation ceramic films formed on AZ31 magnesium alloy. Chin. J. Process Eng. 2009, 9, 592-597.

3. Song, G.; Atrens, A. Understanding magnesium corrosion-A framework for improved alloy performance. Adv. Eng. Mater. 2003, 5, 837-858. [CrossRef]

4. Ponthiaux, P.; Wenger, F.; Celis, J.P. Tribocorrosion: Material Behavior under Combined Conditions of Corrosion and Mechanical Loading. In Corrosion Resistance; Shi, H., Ed.; InTech: Cambridge, UK, 2012.

5. Wood, R.J.K.; Wharton, J.A. Coatings for Tribocorrosion Protection. In Tribocorrosion of Passive Metals and Coatings; Landolt, D., Mischler, S., Eds.; Woodhead Publishing Limited: Cambridge, UK, 2011.

6. Snizhko, L.O.; Yerokhin, A.L.; Pilkington, A.; Gurevina, N.L.; Misnyankin, D.O.; Leyland, A.; Matthews, A. Anodic processes in plasma electrolytic oxidation of aluminium in alkaline solutions. Electrochim. Acta 2004, 49, 2085-2095. [CrossRef]

7. Cao, F.H.; Lin, L.Y.; Zhang, Z.; Zhang, J.Q.; Cao, C.N. Environmental friendly plasma electrolytic oxidation of AM60magnesium alloy and its corrosion re-sistance. Trans. Nonferr. Met. Soc. China 2008, 18, 240-247. [CrossRef]

8. Pezzato, L.; Brunelli, K.; Gross, S.; Magrini, M.; Dabalà, M. Effect of process parameters of plasma electrolytic oxidation on microstructure and corrosion properties of magnesium alloys. J. Appl. Electrochem. 2014, 44, 867-879. [CrossRef]

9. Martin, J.; Melhem, A.; Shchedrina, I.; Duchanoy, T.; Nominè, A.; Henrion, G.; Czerwiec, T.; Belmonte, T. Effects of electrical parameters on plasma electrolytic oxidation of aluminium. Surf. Coat. Technol. 2013, 221, 70-76. [CrossRef]

10. Cao, F.H.; Cao, J.L.; Zhang, Z.; Zhang, J.Q.; Cao, C.N. Plasma electrolytic oxidation of AZ91D magnesium alloy with different additives and its corrosion behavior. Mater. Corros. 2007, 58, 696-703. [CrossRef]

11. Zhuang, J.J.; Song, R.G.; Xiang, N.; Xiong, Y.; Hu, Q. Effect of current density on microstructure and properties of PEO ceramic coatings on magnesium alloy. Surf. Eng. 2017, 33, 744-752. [CrossRef]

12. Shim, G. Factors influencing plasma electrolytic oxidation (PEO) coatings on magnesium alloys: A review. J. Korean Inst. Met. Mater. 2017, 55, 296-307.

13. Pezzato, L.; Brunelli, K.; Babbolin, R.; Dolcet, P.; Dabalà, M. Sealing of PEO coated AZ91 magnesium alloy using La-based solutions. Int. J. Corros. 2017, 2017, 5305218. [CrossRef]

14. Mingo, B.; Arrabal, R.; Mohedano, M.; Llamazares, Y.; Matykina, E.; Yerokhin, A.; Pardo, A. Influence of sealing post-treatments on the corrosion resistance of PEO coated AZ91 magnesium alloy. Appl. Surf. Sci. 2018, 433, 653-667. [CrossRef]

15. Ceschini, L.; Morri, A.; Angelini, V.; Messieri, S. Fatigue behavior of the rare earth rich EV31A Mg alloy: influence of plasma electrolytic oxidation. Metals 2017, 7, 212. [CrossRef]

16. Pezzato, L.; Angelini, V.; Brunelli, K.; Martini, C.; Dabalà, M. Tribological and corrosion behavior of PEO coatings with graphite nanoparticles on AZ91 and AZ80 magnesium alloys. Trans. Nonferr. Met. Soc. 2018, 28, 259-272. [CrossRef]

17. Garsivazjazi, M.R.; Golozar, M.A.; Raeissi, K.; Fazel, M. Evaluation of corrosion and tribocorrosion of plasma electrolytic oxidation treated Ti-6Al-4V alloy. Surf. Coat. Technol. 2014, 244, 29-36. [CrossRef]

18. Barik, R.C.; Wharton, J.A.; Wood, R.J.K.; Stokes, K.R.; Jones, R.L. Corrosion, erosion and erosion-corrosion performance of plasma electrolytic oxidation (PEO) deposited $\mathrm{Al}_{2} \mathrm{O}_{3}$ coatings. Surf. Coat. Technol. 2005, 199, 158-167. [CrossRef]

19. Nie, X.; Meletis, E.I.; Jiang, J.C.; Leyland, A.; Yerokhin, A.L.; Matthews, A. Abrasive wear/corrosion properties and TEM analysis of $\mathrm{Al}_{2} \mathrm{O}_{3}$ coatings fabricated using plasma electrolysis. Surf. Coat. Technol. 2002, 149, 245-251. [CrossRef] 
20. Li, X.; Liu, X.; Luan, B.L. Corrosion and wear properties of PEO coatings formed on AM60B alloy in $\mathrm{NaAlO}_{2}$ electrolytes. Appl. Surf. Sci. 2011, 257, 9135-9141. [CrossRef]

21. Demirci, E.E.; Arslan, E.; Ezirmik, K.V.; Baran, O.; Totik, Y.; Efeoglu, I. Investigation of wear, corrosion and tribocorrosion properties of AZ91 Mg alloy coated by micro arc oxidation process in the different electrolyte solutions. Thin Solid Films 2013, 528, 116-122. [CrossRef]

22. Hornberger, H.; Virtanen, S.; Boccaccini, A.R. Biomedical coatings on magnesium alloys-A review. Acta Biomater. 2012, 8, 2442-2455. [CrossRef] [PubMed]

23. Li, Q.; Linag, J.; Wang, Q. Plasma Electrolytic Oxidation Coatings on Lightweight Metals. In Modern Surface Engineering Treatments; Aliofkhazraei, M., Ed.; InTech: Cambridge, UK, 2013.

24. Blawert, C.; Bala Srinivasan, P. Plasma Electrolytic Oxidation Treatment of Magnesium Alloys. In Surface Engineering of Light Alloys; Dong, H., Ed.; Woodhead Publishing Limited: Cambridge, UK, 2010.

25. Jiang, B.L.; Wang, J.M. Plasma Electrolytic Oxidation Treatment of Aluminium and Titanium Alloys. In Surface Engineering of Light Alloys; Dong, H., Ed.; Woodhead Publishing Limited: Cambridge, UK, 2010.

26. Dehnavi, V.; Shoesmith, D.W.; Li, L.B.; Yari, M.; Yang, L.X.; Rohani, S. Corrosion properties of plasma electrolytic oxidation coatings on aluminum alloys-The effect of the PEO process stage. Mater. Chem. Phys. 2015, 161, 49-58. [CrossRef]

27. Sreekanth, D.; Rameshbabu, N.; Venkateswarlu, K. Effect of various additives on morphology and corrosion behavior of ceramic coatings developed on AZ31 magnesium alloy by plasma electrolytic oxidation. Ceram. Int. 2012, 38, 4607-4615. [CrossRef]

28. Pezzato, L.; Brunelli, K.; Dolcet, P. Dabalà M. Plasma electrolytic oxidation coating produced on $39 \mathrm{NiCrMo3}$ steel. Surf. Coat. Technol. 2016, 48, 729-738.

29. Liang, J.; Bala Srinivasan, P.; Blawert, C.; Störmer, M.; Dietzel, W. Electrochemical corrosion behaviour of plasma electrolytic oxidation coatings on AM50 magnesium alloy formed in silicate and phosphate based electrolytes. Electrochim. Acta 2009, 54, 3842-3850. [CrossRef]

(C) 2018 by the authors. Licensee MDPI, Basel, Switzerland. This article is an open access article distributed under the terms and conditions of the Creative Commons Attribution (CC BY) license (http:// creativecommons.org/licenses/by/4.0/). 